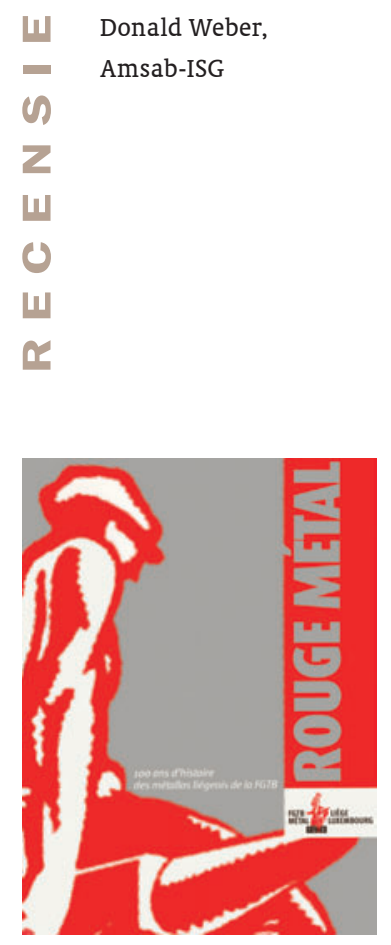

Rouge Métal. 100 ans

d'histoire des métallos

liégeois de la FGTB,

Seraing, Institut

d'histoire ouvrière, économique et sociale (IHOES) / FGTB Métal Liège-Luxembourg, 2006, $255 \mathrm{p}$.

\section{Rouge Métal. 100 ans d'histoire des métallos liégeois de la FGTB}

Het bijzonder fraai vormgegeven boek Rouge Métal vertelt het verhaal van de roemruchte métallos van Luik, de socialistische vakbond van de metaalindustrie. Het is het soort geschiedenis waarvoor men het woord 'legendarisch' zou moeten uitvinden als het al niet bestond, een aaneenrijging van historische hoogtepunten: het oproer van 1886, Julien Lahaut, de stichting van het Algemeen Belgisch Vakverbond (ABVV), GrâceBerleur, André Renard en zijn Mouvement Populaire Wallon (MPW), Cockerill-Sambre... De aanleiding voor deze publicatie was een eeuwfeest, dat van de Fédération Générale du Travail de Belgique (FGTB) Métal LiègeLuxembourg. In 1905 werd op een congres van de nationale federatie van de metaalarbeiders beslist om van start te gaan met een regionale structuur, het jaar erop werd het eerste permanente secretariaat opgericht voor de metaalarbeiders van de provincie Luik. Maar evengoed kan dit werk opgedragen worden aan de lokale afdeling van metaalarbeiders in Seraing, eveneens gesticht in 1905, met de mooie naam Relève-toi!, waarvan de stichters een staalkaart vormen van de latere leiders van de Luikse metallo's: Joseph Bondas, Julien Lahaut, Isi Delvigne, Louis Archembeau enz.

Het boek behandelt chronologisch vier perioden, met de beide wereldoorlogen en de oliecrisis van 1973 als breukmomenten. Afsluitend is ook nog een hoofdstuk opgenomen waarin de houding van de metaalvakbond wordt geduid tegenover de federalisering (in 2006 werd ABVV-Metaal opgesplitst in een Vlaamse en Waalse tak). Voor elke periode worden drie aspecten behandeld: de sociaaleconomische context, de institutionele ontwikkeling van de vakbond en de grote sociale en politieke conflicten van de betrokken periode. 
Het eerste hoofdstuk schetst het ontstaan van de zware metaalindustrie in het Luikse, van de eerste fabrieken van John Cockerill tot de Fabrique Nationale de Herstal, met veel aandacht voor de dagelijkse omstandigheden van de (zware) arbeid in deze industrietak. Maar vooral de bladzijden over de combats trekken de aandacht: het is van bij de aanvang duidelijk dat dit een gewelddadig verhaal wordt, een geschiedenis die niet eenmaal, maar driemaal rood is: van socialisme, van bloed en van vloeibaar metaal.

Les massacres de Seraing van april 1869: het eerste grote, bloedige treffen. Het begint met een staking bij Cockerill, waar de directie de werkduur wil verhogen tot twaalf uur per dag. De mijnwerkers van de putten Caroline, Colard en Guillaume sluiten zich aan bij de stakers, en op 9 april slaat de vlam in de pan: "La cavalerie charge au sabre, tandis que l'infanterie et la gendarmerie jouent de la baïonnette, y compris en forçant la porte des maisons et s'en prenant à la foule qui attend le train en gare de Seraing." (p. 45). De massacres duren vier dagen, er vallen ten minste twee doden en tientallen gewonden. De staking deint uit tot het hele bekken van Luik, maar het is een verloren strijd. Het wordt een volledige nederlaag, de stakingsleiders komen in de gevangenis terecht en de fabrieksbazen houden naderhand 1,15 frank af van het loon van elke staker, 'om de schade te vergoeden'.

Zeventien jaar later, donderdag 18 maart 1886, een banale weekdag in de stad Luik. Enkele anarchisten hebben besloten om een optocht te houden om de vijftiende verjaardag te gedenken van de Commune van Parijs. Ze hopen op een honderdtal deelnemers, het worden er een paar duizend. De menigte trekt door het stadscentrum, schreeuwend 'Vive l'anarchie!' en 'À bas les capitalistes', te dicht bij de burgerlijke winkelstraten volgens de overheid. Bilan op het einde van de dag: 17 gewonden, een 50-tal gearresteerden en verschillende gebouwen vernield. Dan, de volgende ochtend, de steenkoolmijn van Concorde, in Jemeppe, vlakbij Luik. De mijnwerkers zien dat een van hen niet komt opdagen, want gearresteerd bij de rellen van de dag ervoor. Weer staking, het nieuws gaat onmiddellijk rond, de dag erna ligt heel Luik plat. Maar de autoriteiten zijn gealarmeerd en niet van plan om een stap terug te zetten: een vloedgolf van ordestrijdkrachten spoelt door de straten van Luik, zes stakers blijven dood achter. Waarna in het halve land de hel losbreekt...

Geweld blijft de sociale strijd in deze streek kenmerken. De doden van 1902 in Leuven zijn in de herinnering gebleven, maar in 1912 gebeurt iets gelijkaardigs in Luik. De dag na de verkiezingen van 2 juni 1912, verloren door de socialisten, komen er in het hele land spontane stakingen. In Luik breken rellen uit, er wordt gevochten in het centrum van de stad, mensen vluchten het volkshuis La Populaire binnen. De rijkswacht komt bij het volkshuis aan en schiet door de ramen naar binnen, op de opeengepakte menigte. Drie arbeiders overleven de kogelregen niet.

Luik is de cité ardente, de gemoederen van zijn bewoners zijn al even vurig. De Luikse metaalarbeider komt snel op straat, maar keert zich even gemakkelijk tegen het vakbondsgezag. Voor een vakbond is het moeilijk om allen onder één vlag te scharen. Dat begint pas goed te lukken na WO I. Deze oorlog raakt de Luikse me- 

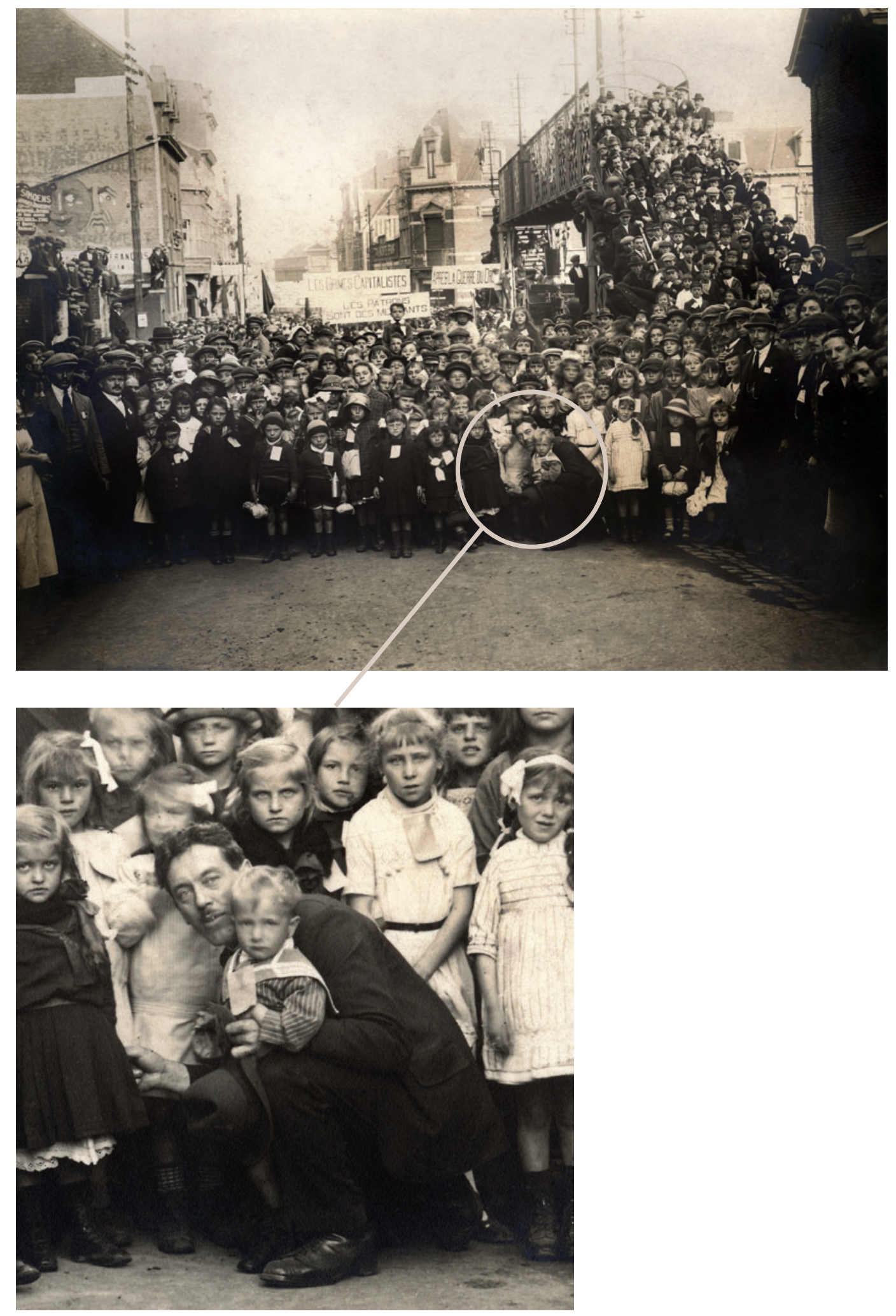
taalindustrie bijzonder hard, maar de sector herstelt zich snel. De vakbond groeit mee, net zoals in het hele land, van 5000 leden vóór de oorlog naar 25.000 in 1919 en meer dan 50.000 eind 1920. De vakbond bereikt op dat ogenblik naar schatting ongeveer $95 \%$ van alle metaalarbeiders in de regio. Maar die piek kan niet aangehouden worden, later stabiliseert het ledental op ongeveer 30.000 leden.

De heroïsche periode is voorbij, het tijdperk van de groene tafel is aangebroken, van leiders die naar voren komen, onderhandelingen, akkoorden, paritaire comités en de congé payé. De grote figuur bij de metallo’s is Isidore 'Isi’ Delvigne. Als 14-jarige knaap begonnen in de fabriek van Cockerill, wordt hij een van de oprichters van de lokale metaalvakbond in Seraing en de stichtende voorzitter van de provinciale metaalvakbond in 1905. Hij zou het blijven, meer dan vijftig jaar lang, tot 1956. Delvigne is ook de stichtende voorzitter van La Wallonie, die van een lokale Luikse bijlage bij Le Peuple uitgroeit tot een zelfstandige regionale krant. Delvigne vormt team met die andere bekende Luikse metallo, Joseph Bondas, eveneens en twee jaar vóór Delvigne als 13-jarige knaap begonnen bij Cockerill. Bondas was de secretaris van de provinciale sectie van de metaalvakbond, maar na WO I eveneens op nationaal vlak, eerst van de Syndikale Kommissie, later van het Belgisch Vakverbond. Joseph Bondas is eveneens bekend als historicus van de beweging, hij is onder meer de auteur van een in 1948 verschenen geschiedenis van de Centrale der Metaalbewerkers.

Maar wellicht de beruchtste naam onder de Luikse metallo's van deze periode is die van Julien Lahaut, de in 1950 vermoorde communistische politicus, die twee jaar later dan Delvigne als 14-jarige bij Cockerill was begonnen en nog samen met hem de metaalvakbond van Seraing had opgericht. Communist was Lahaut nog niet in 1921, toen de grote staking van Ougrée-Marihaye uitbrak. De gebeurtenissen in en rond Ougrée-Marihaye vormen een zwarte bladzijde in de geschiedenis van de Luikse metaalvakbond en het siert de makers van Rouge Métal dat ze de episode niet uit de weg zijn gegaan. Het begint als een banaal protest, in maart 1921, in een metaalfabriek, tegen een al te strenge fabrieksbaas. Er wordt heen en weer getrokken tussen beide partijen, stakingsbrekers komen erbij en tegen mei ligt de hele fabriek plat. Op dat moment evolueert het conflict en komen interne spanningen in de metaalvakbond op pijnlijke wijze bloot te liggen: spanningen tussen Delvigne, aanhanger van de Internationale van Amsterdam en voorstander van onderhandelingen, en Lahaut, aanhanger van de communistische internationale, die zegt 'zijn basis te volgen'. In november eindigt de staking, het is een volledige mislukking. Vier maanden later slaat de vakbondsleiding keihard terug en schopt Lahaut en zijn aanhangers uit vakbond én partij. Waarna de metaalvakbond $40 \%$ van zijn leden verliest, waarna Lahaut bij de KP gaat, enzovoort. Het is het verhaal van de rode broederstrijd uit deze periode dat al tot treurens toe in geschiedenisboeken is verteld geworden. En soms vertelt een beeld meer dan woorden dat kunnen: een foto ten

Foto genomen tijdens de grote staking van Ougreé-Marihaye.

In het midden Julien Lahaut met een kindje op schoot (Amsab-ISG) 
tijde van de staking, je ziet een straatbeeld in een wat groezelige buurt. Een grote menigte poseert voor de foto, de volwassenen allen langs de kanten, op de trottoirs, de meesten met de 'klak' op, in het midden van de straat hun kinderen. Leuk, denk je, kindjes, met van die grappige kleine klakjes op. Maar dan lees je het bijschrift en het slaat je koud om het hart: "Afin de permettre aux travailleurs de supporter les difficultés de la grève d'Ougrée-Marihaye [...], et selon une tradition ouvrière de solidarité [...], des centaines d'enfants sont pris en charge par des familles d'accueil à travers tout le pays." (p. 87). In het midden van de straat, één volwassene, geknield tussen de kinderen en met een kleuter op zijn schoot: Julien Lahaut.

Dan volgt de episode van WO II, voorafgegaan door de Spaanse Burgeroorlog. Opnieuw trekt de grote geschiedenis de Luikse regio in haar kielzog mee. En opnieuw vertelt een beeld een verhaal. We zien een sprekerstafel, Isi Delvigne staat erachter, rechtop, hij spreekt het congres toe van de Luikse vakbonden, in 1939. Naast hem zitten enkele bestuursleden, onder meer secretaris Joseph Bondas. En zie, opnieuw komen kinderen in beeld: op de schoot van Bondas en naast hem zitten een jongen en een meisje mee op het congrespodium. Het bijschrift zegt: "Joseph Bondas siège à ses côtés en compagnie de ses deux enfants adoptés, Augusta et Ramon. Ce dernier était fils de républicains espagnols [...], des centaines d'enfants sont pris en charge par des familles d'accueil à travers tout le pays." (p. 98).

Tijdens de bezetting duikt een nieuwe, snelbekende naam op: André Renard, een medewerker van de studiedienst van de Luikse metaalvakbond sinds 1937. Renard wordt in het begin van de oorlog krijgsgevangen, maar wegens ziekte vrijgelaten. Hij keert in mei 1942 terug naar het Luikse, waar hij door Isi Delvigne met een bijzondere missie belast wordt. Sinds midden 1941, na de Duitse inval in de Sovjet-Unie, waren de communisten uit hun schuilhoek gekomen. Zowat overal op de werkvloer, en dus zeker in de grote Luikse metaalfabrieken, werden vakbondscellen opgericht. In mei 1941 was er al een grote staking losgebroken, la grève des 100.000. Vanaf midden 1942 begint Renard aan een tegenbeweging: hij richt zijn eigen vakbondscellen op in fabrieken als Les Tubes de la Meuse, OugréeMarihaye, Espérance-Longdoz, Cockerill, Les Ateliers Jaspar, Marichal Klein enz. Eerst noemt hij zijn beweging Mouvement Métallurgiste Unifié (MMU), later breidt ze uit naar andere industrietakken. Renard publiceert eveneens een beginselverklaring, Pour la Révolution constructive, en slaagt erin om de communisten het gras van voor de voeten te maaien en vanuit de Luikse metaalindustrie een alternatief aan te bieden voor de naoorlogse vakbeweging. Volgt het einde van de oorlog en opnieuw haalt de grote geschiedenis de Luikenaars in: bij de stichting van het ABVV zitten twee Luikse metallo's in een prominente positie: Bondas voor de 'oude' socialistische vakbond en Renard voor zijn Mouvement Syndical Unifié (MSU). André Renard en het door hem ontwikkelde 'renardisme' (een syndicalisme gericht op economische democratie en directe actie) zullen in de decennia na WO II het gezicht bepalen van de Luikse metallo's. Gewelddadige conflicten blijven intussen een kenmerk van het Luikse syndicalisme (de titel van een door Renard in 1961 gelanceerd syndicaal blad is trouwens Combat). 


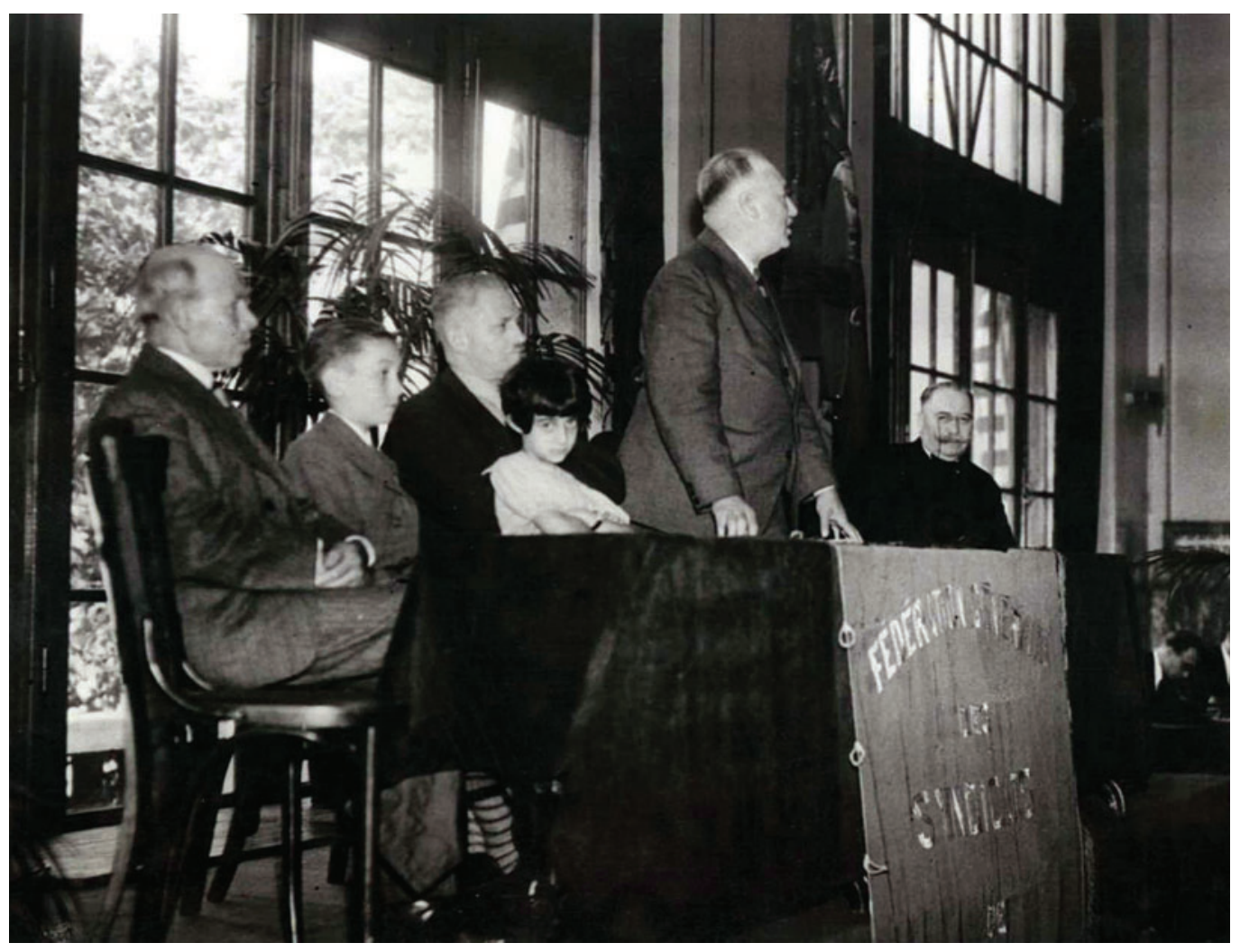

Isi Delvigne aan het woord op het congres van het Belgisch Vakverbond in 1939. Links van hem Joseph Bondas met zijn twee geadopteerde Spaanse kinderen, Augusta en Ramon (Form'action André Renard)

Een mooie zondag in de zomer van 1950, Grâce-Berleur, vlakbij Luik. Een week vroeger is Leopold III teruggekeerd uit ballingschap, tegen de wil in van een grote meerderheid van de Walen. Het is namiddag en een groep arbeiders verzamelt voor een meeting, ondanks een officieel verbod. De rijkswacht schiet de bijeenkomst uit elkaar, vier arbeiders sterven onder de kogels. De volgende dag, Luik, een groep mannen verzamelt in het gebouw van de vakbond. Op de agenda: afscheuring van Wallonië, vorming van een voorlopige regering en bijeenroepen van een Waalse Staten-Generaal. Tegelijk wordt een mars op Brussel voorbereid. Koning Leopold laat het niet zover komen en treedt af.

Tien jaar later, in de winter van 1960-61, met de grote staking tegen de Eenheidswet, staat het land opnieuw in brand. De 'staking van de eeuw' begint voor één keer niet in Luik, maar in Charleroi, waar de metallo's van ACEC op 20 december 1960 de machines stilleggen. Maar de voorbereiding was in Luik gebeurd, met een door André Renard bijeengeroepen 'concentratie' op 14 december, waar 50.000 
demonstranten op afgekomen waren. Diezelfde Renard neemt resoluut de leiding van de staking in handen, aarzelend gevolgd door een weifelend ABVV-bestuur. Luik blijft heel de staking door de brandhaard van het conflict: aan het station van Guillemins vallen 75 gewonden in gevechten met de politie, in Chênée wordt de bekende bokser Jo Woussem te midden van een groepje stakers gedood door een politiekogel. Wanneer de staking eindigt, op 21 januari 1961, staat enkel het bataillon de fer nog overeind, de metallo's van Charleroi en Luik. Renard, gedegouteerd, stapt uit het ABVV en richt zijn eigen beweging op, de MPW. Hij wil weg van een vakbond die al te sterk aan een in zijn ogen reformistische socialistische partij gebonden is, maar ook weg van een door patroons en ACV gedomineerd Vlaanderen. Renard overlijdt een jaar later, maar zijn MPW zou de politieke kaart van België grondig hertekenen.

Legendarisch eveneens is zonder twijfel de grote 'vrouwenstaking' van 1966. In Herstal, in de Fabrique Nationale d'Armes de Guerre (FN) breekt in februari 1966 een staking uit die in grote meerderheid wordt gedragen door vrouwelijke arbeiders. Zij vragen iets wat voor de hand lijkt te liggen: 'À travail égal, salaire égal'. Dat is een simpele eis, niets anders dan de uitvoering van de wet waarmee België het Verdrag van Rome heeft goedgekeurd, dat dit principe dwingend oplegt. Meer dan drieduizend arbeidsters gaan in staking, drie maanden lang, een uitzonderlijk evenement dat in heel Europa reacties en steunbetuigingen uitlokt. Meeting na meeting vindt plaats in de zaal van de coöperatie La Ruche in Herstal, tweemaal trekt een betoging van duizenden vrouwen (en enkele mannen) door de straten van Herstal. Een wetsvoorstel voor gelijke lonen voor mannen en vrouwen wordt in het parlement ingediend. En weer toont Rouge Métal ons een sterk beeld: zaal La Ruche, een vakbondsmeeting, een frontale blik op het podium, vier heren zitten neer achter een tafel. Maar het beeld wordt beheerst door een vijfde figuur. Het is een vrouw, ze zit niet neer maar staat recht, vóór de tafels. Met haar ene hand houdt ze een staande microfoon vastgeklemd, haar andere heeft ze uitdagend in haar zij geplant. Ze draagt werkkleding, een overall, en een hoofddoek die onder haar hals is geknoopt. Ze kijkt recht de zaal in, kin omhoog en haar mond is half open want ze houdt een krachtige toespraak. Het is geen excuustruus die we hier zien, geen etalagesyndicaliste, dit is écht: the times they are-a-changin...

De laatste hoofdstukken van het boek zijn niet zo heroïsch meer van aard, al zijn ze niet minder dramatisch. Het is de trieste saga van de oliecrisis en van de teleurgang van de Waalse staalindustrie, van Cockerill Sambre en Jean Gandois, van een après-renardistische vakbond die meer tijd moet steken in overleven dan in aanvallen.

De redactie van dit jubileumboek werd toevertrouwd aan het Luikse documentatiecentrum Institut d'histoire ouvrière, économique et sociale (IHOES). Dit centrum werd in 1979 opgericht door de gedreven verzamelaar van socialistica Michel Hannotte, toen werkzaam als bibliothecaris in de Luikse stadsbibliotheek Les Chiroux. Het was aanvankelijk een fonds binnen deze bibliotheek. Eind jaren 1980 kwam het IHOES in 


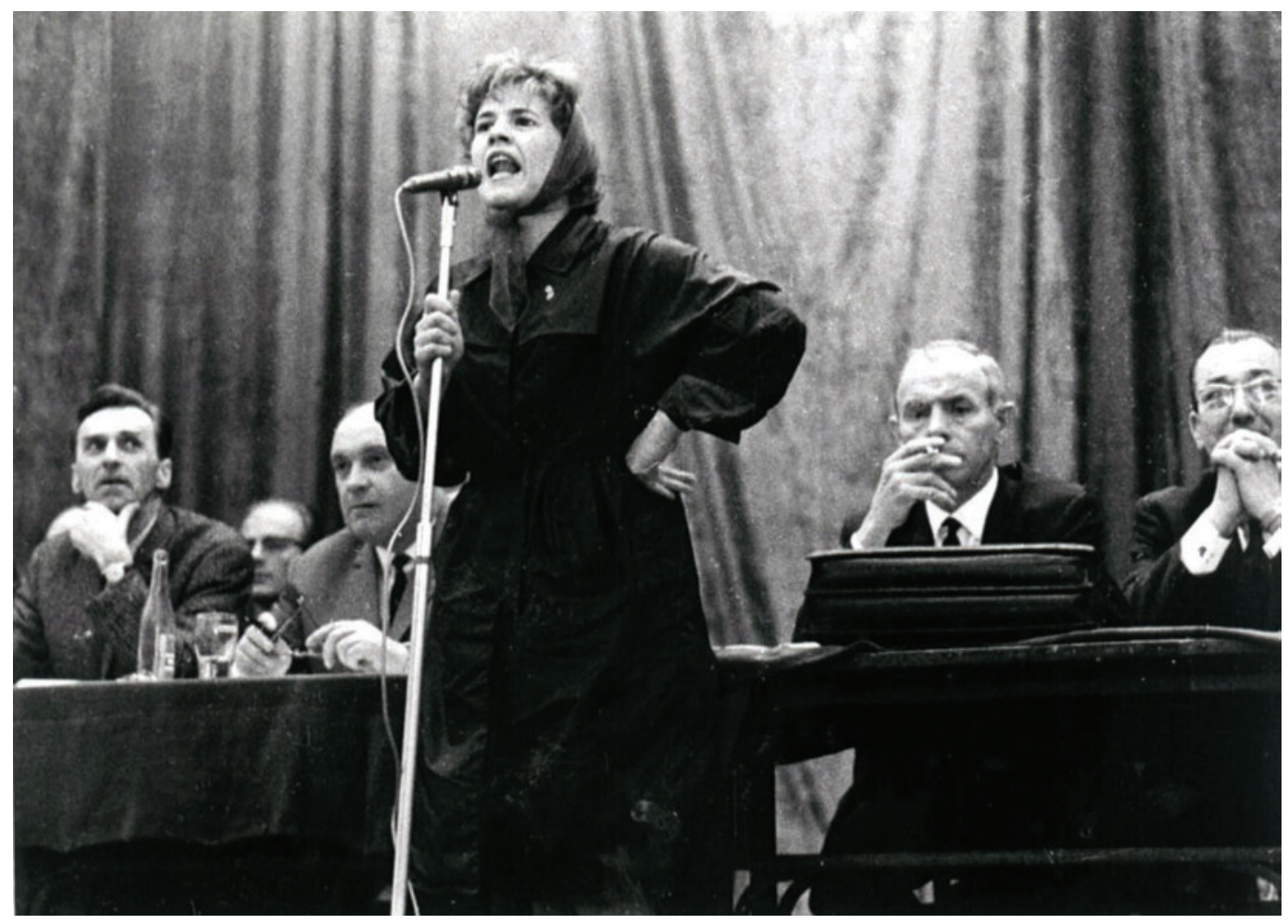

Meeting in FN Herstal. Vooraan: Charlotte Hauglustaine, voorzitter van het stakerscomité 'À travail égal, salaire égal' (Form'action André Renard)

de problemen, toen de stad Luik gedwongen werd tot besparingsmaatregelen en Hannotte en zijn fonds op straat kwamen te staan. Hannotte gaf echter niet op, maakte van zijn instituut een vzw en slaagde erin om via het decreet op de private archiefinstellingen van 1994 van de Franse Gemeenschap een erkenning te krijgen. Momenteel telt het instituut vijf medewerkers. Het is gevestigd in het Luikse in Jemeppe (Seraing), vlak bij de oever van de Maas, met een indrukwekkend zicht op de hoofdvestiging van Cockerill Sambre aan de overkant. De collectie omvat momenteel ongeveer 2,5 km archieven, daarnaast zijn er een bibliotheek met meer dan 40.000 titels en een omvangrijke iconografische verzameling. De archief- en bibliotheekdocumenten worden ontsloten via Pallas, raadpleegbaar op de IHOES-website.

Een gedeelte van de iconografische voorwerpen wordt daarnaast ontsloten via het project Les Archives du Travail. Dat is dan weer een product van GrenzGeschichte, een driejarig Europees project dat einde 2006 werd afgesloten in het kader van de interregionale Europese samenwerking voor de regio Maas-Rijn. De website www. archivesdutravail.org werd gemaakt door FAR en biedt momenteel collectiemateriaal aan van FAR en IHOES (voornamelijk iconografisch). FAR staat tegenwoordig 
voor Form'action André Renard en werd oorspronkelijk in 1963, na de dood van Renard, opgericht als Fondation André Renard. Dit centrum bevat een aantal persoonlijke archieven, materiaal van onder meer Bondas, Delvigne en Renard, maar profileert zich vandaag veeleer als vormingscentrum van de Luikse socialistische vakbond. FAR heeft intensief meegewerkt aan het maken van Rouge Métal.

Maar terug naar IHOES. Het instituut organiseert regelmatig tentoonstellingen en conferenties. Er is een aanbod van verschillende rondreizende tento's op panelen, die kunnen gehuurd worden. Bijvoorbeeld uit 2007: Cara a España. L'immigration espagnole en région liégeoise: histoire et mémoire des clubs Federico García Lorca. Wie op de hoogte wil blijven van de activiteiten, kan zich via de website aanmelden voor een digitale lettre d'information. Sinds 1993 heeft het instituut negen publicaties op zijn naam staan, waaronder huldeboeken aan Willy Peers, Jacques Yerna en Paul Daxhelet. Verder ook studies over het verzet in de Luikse regio, de staking van 1932, de clandestiene pers in Seraing enz. Daarnaast heeft het instituut op zijn website een interessant aanbod van themadossiers die kunnen gedownload worden, er zijn momenteel 25 titels beschikbaar. Rouge Métal is zonder meer de aanzienlijkste publicatie van het instituut tot dusver.

Voor de realisatie van het boek deed IHOES een beroep op een wetenschappelijk comité, bestaande uit Éric Geerkens, Robert Halleux, Rik Hemmerijckx, Freddy Joris, Philippe Raxhon en Pierre Tilly. Niet minder dan twintig namen van auteurs worden vermeld, er is echter geen aanduiding van wie wat geschreven heeft. Wel werden twee korte bijdragen opgenomen, van Hemmerijckx over de moeizame verhouding met de communisten en van Tilly over Renard en het renardisme.

Rouge Métal is in de eerste plaats bedoeld als boek van de vakbond voor de vakbond: FGTB Métal Liège-Luxembourg probeert hiermee de eigen (jonge) militanten inzicht te geven in de strijdpunten van het heden en het verleden en hun een bredere historische context aan te bieden. Daar is niets mis mee en de aanzienlijke hoeveelheden syndicale propaganda nemen we er dan ook zonder problemen bij. Doordat de publicatie uitgaat van een lokale organisatie, laat zij toe om de geschiedenis die ze beschrijft door te voeren tot real time level, om, met andere woorden gezichten, plaatsen en tijdstippen op de gebeurtenissen te plakken. Dat geeft een heel ander perspectief dan wat soms al te abstract beschreven staat in nationale geschiedenisoverzichten; dat de regio in kwestie dan nog verreweg de actiefste is geweest in de Belgische sociale geschiedenis maakt dat dit werk van eminent belang is. $\mathrm{Al}$ is deze historische studie zeker geen eindpunt. In zijn Woord Vooraf drukt voorzitter Gomez trouwens zijn verbazing uit over het gebrek aan historisch onderzoek naar de Luikse sociale geschiedenis: "Au bout du compte, il apparaît aussi que cet ouvrage comble une lacune: rien de solide n'existait non seulement sur l'histoire de notre FGTB Métal, mais aussi sur l'histoire de toute une série d'événements auxquels elle est indissolublement liée. Qu'il soit permis à un modeste syndicaliste, formé à l'école du travail, de s'étonner qu'au total, l'histoire sociale liégeoise soit si peu un centre d'intérêt pour les chercheurs, d'ici ou d'ailleurs." (p. 6) 
Ten slotte moet gewezen worden op wat misschien nog de allergrootste kwaliteit is van dit werk: de illustraties. Het boek is waarlijk verbluffend mooi geïllustreerd. Er zijn honderden afbeeldingen opgenomen, in kleur en van hoge kwaliteit. De beelden zijn relevant gekozen en zodanig geplaatst dat ze de tekst niet enkel 'verluchten', maar een essentiële visuele aanvulling bieden op de beschreven feiten. Ze zijn voorzien van uitvoerige en erg verhelderende bijschriften, bovendien is achteraan het werk een twaalf bladzijden tellende bijlage opgenomen, waarin van elke afbeelding een uitgebreide steekkaart is opgenomen. Dit is een boek gemaakt door mensen die van boeken houden, het soort boek dat je eraan herinnert waarom er zoiets bestaat als papier, een boek dat zelfs een 'peau dure-syndicalist' ervan kan overtuigen een burgerlijk salontafeltje aan te schaffen - al was het alleen maar om dit boek op te kunnen leggen.

http://www.ihoes.be

http://www.far.be

http://www.archivesdutravail.org 